\title{
Como Reatar a Conversa com Corpos Desiguais
}

\begin{abstract}
Beto Vianna ${ }^{1}$
${ }^{1}$ Universidade Federal de Sergipe, Itabaiana, SE, Brasil

\section{Resumo}

Neste artigo, discuto ambiente, percepção e comunicação a partir de uma visão sistêmica do organismo e de seus processos relacionais, em particular seu espaço de encontros coontogênicos, seguindo as coerências da Biologia do Conhecer. Para tanto, examino pressupostos das ciências cognitivas, em que concebemos a linguagem como capacidade específica do humano. Na abordagem da biologia que uso aqui, a linguagem é um fenômeno relacional e pertence ao domínio do comportamento, isto é, a história das relações que o organismo estabelece em um meio. No mesmo caminho explicativo, a percepção é gerada na observação dessa dinâmica de ações do organismo. Assumir esse ponto de partida biológico para falar de ambiente, percepção e comunicação (ou linguagem) pode nos ajudar, acredito, a refletir sobre as certezas ontológicas de nosso afazer científico e suas consequências ao lidarmos com outros modos de vida, geradores de outros domínios de ação e de outros domínios explicativos, humanos ou não.
\end{abstract}

Palavras-chave: Linguagem. Percepção. Ambiente. Biologia do Conhecer. Coontogenia.

\section{How to Restart Conversation with Different Bodies}

\begin{abstract}
In this paper, I discuss environment, perception and communication from a systems view of the organism and its relational processes, in particular its space of coontogenic encounters, following the coherences of Biology of Knowledge. To this end, I examine assumptions of the cognitive sciences, in which we conceive language as a specific human capacity. In the biological approach I use here, language is a relational phenomenon and belongs to the behavioral domain, that is, the history of relations an organism establishes in a medium. In the same explanatory path, perception is generated by observing the dynamics of the organism's actions. I believe that, taking this biological starting point to talk about environment, perception and communication (or language) may help us to rethink the ontological certainties generated by our scientific activities, and its consequences when dealing with other ways of life, and with other action and explanatory domains, human or not.
\end{abstract}

Keywords: Language. Perception. Environment. Biology of Knowledge. Coontogeny. 


\section{Introdução}

$\mathrm{T}$

rato neste texto do tema "Ambiente, comunicação, percepção", proposto em mesa redonda da VII Reunião da Antropologia da Ciência e da Tecnologia (ReAct) em Florianópolis, em 2019, a partir de minhas preocupações acadêmicas, e esperando que elas sejam úteis em uma conversa comum. Como não sou antropólogo da ciência, ou antropólogo de qualquer tipo, mas linguista, minha atenção estará voltada para o fenômeno da linguagem, ainda que eu não faça isso em total acordo com os cânones da minha disciplina. E embora eu não seja, além disso, biólogo, os fundamentos da explicação que vou oferecer para o fenômeno da linguagem são biológicos. Finalmente, mesmo que o que se entenda por uma biologia da linguagem nas ciências cognitivas nos leve a assumir, como princípio explicativo, que a linguagem é uma capacidade exclusiva dos membros da espécie humana, o ponto de partida biológico que utilizo aqui só me permite dizer que a linguagem, como um fenômeno necessariamente relacional, pertence a um domínio comportamental. O comportamento, por sua vez, compreende a história das relações que um organismo (em sua totalidade) estabelece em um meio, com parte desse meio, que pode ou não ser outro ou outros organismos (VIANNA, 2011). Assumir o fenômeno da linguagem como um membro da classe dos fenômenos pertinentes ao domínio do comportamento implica não haver nenhum determinante fisiológico que circunscreva a linguagem no operar dos membros de uma linhagem específica de organismos, ou, indo diretamente ao ponto, que nos obrigue a derivá-lo exclusivamente, e de antemão, do operar de organismos humanos. Espero deixar mais claro, adiante, o que chamo (seguindo outros autores) de domínio comportamental, e por que ele é crucial para a explicação biologicamente fundamentada da linguagem que defendo aqui.

Tal como fiz em minha exposição na ReAct, lanço aqui três perguntas que irão orientar minha abordagem da percepção, do ambiente e da comunicação (e das relações que esses domínios ou fenômenos estabelecem entre si) e deverão, além disso, ajudar a esclarecer por que penso que uma boa maneira de falar da percepção, do ambiente e da comunicação, é fazendo referência ao fenômeno da linguagem. Minhas perguntas propostas são, enfim, as seguintes:

1) Se uma árvore cai em uma floresta desabitada e nenhum animal está por perto para ouvir, o tombar da árvore faz um som?

2) Como é ser um carrapato?

3) Que processos devem ocorrer no organismo para que ele estabeleça um domínio linguístico com outro organismo? 
A pergunta l é um experimento mental popular dentro da pergunta filosófica pela percepção, mas que pode nos levar a reflexões interessantes dentro das (e sobre as) abordagens cognitivas e biológicas do perceber. A segunda pergunta é uma apropriação (ou paródia, se se quiser) do famoso artigo-pergunta do filósofo Thomas Nagel (1974), "What is it like to be a bat?", que transubstanciei no carrapato para, com alguma ajuda do Umwelt de Jakob von Uexküll (2017), tentar escapar das alternativas existenciais sujeito-ou-objeto que aquele primeiro autor coloca. Finalmente, reproduzo, em 3, a pergunta formulada pelo biólogo chileno Humberto Maturana (1978) em um texto seu que compõe uma coletânea em homenagem ao linguista Eric Lenneberg, conhecido por seus estudos pioneiros dos aspectos biológicos da linguagem. A resposta que Maturana dá a essa pergunta, mesmo com algumas ressalvas pessoais que farei durante o texto, tem me ajudado a refletir e discorrer sobre o caráter irredutivelmente relacional da linguagem.

\section{Um Corpo que Cai}

Perguntar se o som surge em uma árvore que tomba na floresta, independentemente de haver alguém por perto capaz de ouvi-lo, não coloca em cheque, necessariamente, uma descrição objetiva do fenômeno acústico, mas diz respeito à possibilidade, nem sempre levada à sério na tradição da ciência ocidental, de não apontarmos consensualmente para um mesmo fenômeno. Respondendo positivamente à pergunta, especificamos o fenômeno "som" dentro das coerências descritivas, por exemplo, dos físicos. Esses cientistas, cuja reformulação do fenômeno auditivo passa por intricados aparelhos de medição e mediação, irão validar a existência de um som independente do escutar. De fato, essa pergunta, do modo como formulada na introdução, aparece pela primeira vez em um livrinho de física do início do século XX (MANN; TWISS, 1910). Ali, como em outros manuais de física acústica, som são as variações de pressão propagadas em um meio (digamos, o ar), causadas por uma perturbação física (o impacto da árvore no solo), o que não exclui sua propagação em um meio orgânico. Contudo, sendo a audição um dado da experiência de organismos que escutam (mediado ou não pela técnica), a pergunta enseja a reposta contrária e igualmente objetiva, de psicólogos e neurocientistas, de que não basta haver perturbação do aparelho auditivo, mas essa deve ser reconhecida pelo organismo (na mente, em seus centros nervosos, ou em ambos, a depender do pendor epistemológico do cientista). Finalmente, sendo um dado da experiência do organismo (inclusive, humano), o som (ou o escutar o som) desperta a atenção dos filósofos da mente e cientistas cognitivos.

Desde Locke e sua mente primeira, ou um "olho da mente" (RORTY, 1995, p. 151), nos perguntamos (ou disputamos acaloradamente) se os sentidos captam uma realidade externa (a árvore-que-cai causa o som, por isso o escutamos) ou se criamos, como sujeitos do cogito, nossas próprias regras de como ter percepções (tudo o que há são "dados dos sentidos"). Negar haver áudio sem audiência, e outras não percepções equivalentes, faz parte da formulação do subjetivismo idealista de Berkeley (1982), que recusa, no início do século XVIII, as existências desapercebidas, mas também é uma heresia comum, de maneiras e com propósitos distintos, nos desenvolvimentos mais recentes 
das filosofias da mente e da linguagem. Estamos falando do conceito de representação, e, daí, de representações privilegiadas (algumas cognições são mais cognitivas que outras), que une teorias do conhecimento das mais variadas cores e sabores. Como no quarto argumento de Berkeley (1982, p. 21), de que “[...] não é possível nem ao menos conceber um objeto fora da mente [...]", o princípio explicativo da representação assegura que tenhamos (nós, sujeitos) internalidades variáveis em meio à continuidade do mundo natural (eles, objetos) lá fora.

Do lado de uma biologia do comportamento e da cognição, a situação é semelhante à dos epistemólogos, o que não surpreende, se lembrarmos que nessa seleta e colonizada rede de conversas que é o universo acadêmico, os sons emitidos por filósofos e cientistas são mutuamente ouvidos. Nas disciplinas dedicadas ao comportamento humano e animal (a psicologia evolutiva, comparada e do desenvolvimento; a etologia; a ecologia comportamental), os relatos de que o paradigma behaviorista foi desbancado por etólogos como Lorenz, e, logo adiante, por novos cientistas cognitivos como Chomsky, costumam fazer referência à reabilitação da mente como objeto legítimo de inquirição ${ }^{1}$, incluindo a noção de que a competência cognitiva está distribuída desigualmente entre as linhagens de organismos, tão sujeita à ação da seleção natural (ou outro mecanismo de ramificação filogenética) quanto a morfologia. É essa confiança em cognições mais ou menos privilegiadas que permite a psicólogos evolutivos e ecologistas comportamentais afirmarem coisas como "[...] a seleção favoreceu os receptores capazes de antecipar o comportamento futuro dos emissores [...]" (KREBS; DAVIES, 1996, p. 358), ou a linguistas cognitivistas dizerem que a habilidade de selecionar, do complexo input auditivo, as características fonologicamente relevantes, desenvolve-se independente de reforço, através da maturação geneticamente determinada (CHOMSKY, 1959). Noam Chomsky, que nunca foi entusiasta de explicações adaptacionistas, junta-se aos etólogos quando diz que que é preciso considerar a estrutura de um organismo específico para compreender os processos envolvidos na origem e no desenvolvimento de um comportamento, como é o caso do escutar.

As duas hipóteses (o comportamento auditivo é geneticamente determinado e, sua maturação, específica da espécie) estão presentes na famosa resenha de Chomsky (1959) do livro Verbal behavior, de Skinner (1992), publicado originalmente em 1957. A resenha marca, na cosmogonia acadêmica, a ascensão do cognitivismo em relação inversa à confiança no behaviorismo, acusado de ignorar a realidade (e a agência) de nossas potentes internalidades. Ainda que Chomsky não se refira a animais escutando árvores tombando na floresta, mas a crianças humanas ouvindo os sons de seus coespecíficos, a premissa é a mesma. As propriedades internas (neurofisiológicas, mentais) de organismos específicos selecionam representações distintas, às vezes mais acuradas, ou mesmo (como na linguagem) exclusivas, do ambiente. Em condições semelhantes (e haveria mais a dizer sobre o que conta como condições semelhantes), uma criança humana aprende mais sobre as possibilidades combinatórias de sua língua materna do que efetivamente

\footnotetext{
Ver, por exemplo, os Capítulos 1 e 2 do livro de Howard Gardner (1996, p. 25-60) e o segundo capítulo de Donald Griffin (2001, p. 20-36) sobre, respectivamente: o "desafio ao behaviorismo"; as origens das ciências cognitivas (no mito de origem cognitivista de Gardner, claro); e as "objeções e limitações" a uma etologia cognitiva, ou à aceitação de uma consciência animal.
} 
escuta, e um filhote chimpanzé, não importa a quantos audiobooks seja exposto, não irá apreender, de qualquer língua humana, muito mais que um rumor indistinto - ver, no entanto, Savage-Rumbaugh e Lewin (1994) sobre as performances auditivas do bonobo Kanzi.

Voltando às possibilidades acústicas de nossa árvore cadente, de acordo com os paradigmas de inspiração representacionista, não apenas deve haver um organismo que perceba o som e comande, como o deus hebreu, fiat vox, mas o processamento interno do som percebido será diferente para diferentes linhagens de organismos, ensejando comportamentos (respostas, no jargão etológico) também desiguais para cada organismo escutador. Desde "é melhor eu dar o fora daqui", a "tal árvore caiu porque estava podre", as reformulações da experiência som-da-árvore-caindo compõem uma escala hierárquica de organismos, conformando o comportamento de, digamos, um humilde inseto dotado de órgãos auditivos até um humano com pós-graduação em botânica. O que, penso, une o naturalismo dos físicos (o som tem tais e tais propriedades que o definem) ao naturalismo dos cientistas cognitivos (propriedades internas distintas dos organismos geram distintas experiências acústicas), além do fato mais evidente de ambos aderirem à ontologia mononaturalista e multiculturalista de estirpe ocidental - como descrita nas categorias propostas por Descola (2014) - é uma confiança na factualidade dos relatos de terceira pessoa sobre conteúdos sobre a natureza, que garantem a continuidade do mundo natural não apenas do ponto de vista de um monismo físico do tipo "nada além" (escutar é nada além que a versão orgânica do fenômeno acústico), mas nos dualismos que preservam a autonomia fenomenológica de uma internalidade variável. Essa internalidade pode muito bem ser identificada com o termo "cultura", como no binômio natureza-cultura, mas distribuída não apenas entre os modos humanos de lidar com o mundo, mas entre representações do ambiente com graus variados de acuidade que, se continuam garantindo à subjetividade humana a mesma distância segura da objetificação natural (distância tão cara às antropologias do simbólico), concede espaços igualmente apartados da natureza (se bem que mais apertados) à cognição de organismos quase-humanos: protoculturas, protolinguagem, protoconsciência e, dispensando o prefixo, senciência.

A noção de representações mais ou menos privilegiadas do ambiente tanto dá suporte a escolas descontinuístas ( só o humano...) quanto cautelosamente continuístas (em certos aspectos, também os animais...). Cientistas cognitivos, certos psicólogos comparativos (TOMASELLO, 2003) e a maioria dos biólogos evolutivos e comportamentais, apesar de enfatizarem uma continuidade natural subjacente, costumam se posicionar entre os primeiros. Do segundo tipo, há aquelas e aqueles que: reivindicam o fenômeno da consciência para alguns animais, tanto em uma mirada evolutiva (GINSBURG; JABLONKA, 2019), quanto sincrônica (GRIFFIN, 2001); atribuem cultura(s) para seus sujeitos de investigação (BOESCH, 2013); relativizam a descontinuidade linguística, em especial nos ape language studies (GARDNER; GARDNER, 1989; SAVAGE-RUMBAUGH; LEWIN, 1994); e, seja em uma perspectiva utilitarista (SINGER, 2007) ou abolicionista (REGAN, 2007), reivindicam para os organismos sencientes, mas só os sencientes, o direito a serem sujeitos de direito.

Se voltarmos à pergunta sobre o som da árvore-que-cai (formulada, como mencionei, como no livrinho de física), vemos que o contexto é a árvore caindo em uma floresta 
"desabitada", acrescentando que "nenhum animal está por perto para ouvir". Esse modo de colocar o problema marca uma diferença crucial dentro da classe dos sistemas vivos (e não vivos, aliás, mas vou me ater aqui à questão do viver): aqueles cujo existir não "habita" um espaço (a própria árvore e outros elementos da floresta) e aqueles cujo comportamento implica uma reformulação da experiência, validando ou não a realidade da própria experiência. Se o som, segundo a física, propaga-se "em um meio", tal distinção implica que alguns corpos (além de cair) nada mais podem fazer a respeito do som que servir de meio. Nessa perspectiva, por conta de suas filiações naturais, alguns corpos, como as árvores, estão fadados a compor mudos (e surdos) a paisagem, e outros, por outro lado, a ajudar a pintá-la.

\section{O Delicado Som do Trovão}

Escutar um som. Escutar o som de uma árvore atingindo o solo ao cair. Reformular a experiência auditiva com graus distintos de corroboração de uma realidade independente. Configura-se nas abordagens representacionistas, à imagem da Cadeia do Ser de Arthur Lovejoy (2001), a Grande Cadeia da Cognição, reduzida a uma corrente de apenas dois elos quando o que está em questão é a linguagem (VIANNA, 2011). As ontologias representacionistas, que não são novas no ocidente moderno, mas ganharam poder explicativo quase-universal com as ciências cognitivas dos anos 1950 em diante, sugerem, irão me perdoar Tânia Stolze Lima (1996) e Eduardo Viveiros de Castro (1996), um perspectivismo naturalista: a realidade faz-se visível (ou mais nítida) para quem compartilha representações privilegiadas (e, não, necessariamente, um mesmo corpo), especialmente os humanos, e em particular os filósofos e cientistas (mas, não, os xamãs), capazes de atribuir perspectiva a outros seres, vendo-os como quase-humanos. É a perspectiva (per specere, ver de determinado modo) como percepção (per capere, captar a realidade lá fora): a codificação da experiência perceptiva numa matriz cognitiva, corroborada por uma realidade independente. Parafraseando quase no limite do plágio Viveiros de Castro (1996, p. 144), a aparente contradição entre um "etnocentrismo" do cientista, que rejeita (ou trata com condescendência) reformulações da experiência dos humanos não modernos, e um "animismo" do mesmo cientista, que estende (até certo ponto) a outros seres capacidades cognitivas distintivas do humano, pode ser resolvida se se considerar, em relação complementar, a posse de representações mais ou menos privilegiadas (validadas por uma natureza objetiva) e a filiação evolutiva desses organismos (que codifica a variação em suas naturezas internas).

Com o filósofo Richard Rorty, penso, no entanto, que deslocar a causa ou a origem de nossas percepções, do mundo de objetos lá fora, para um olho (no caso, um ouvido) interno da mente, ou, como fazem os filósofos da linguagem, para as representações codificadas nas línguas humanas (ou da língua ainda mais acurada da ciência), continua, como nas regras do jogo de pingue-pongue (que autorizam a bola alternando entre os lados da mesa), legitimando a esperança representacionista de que o operar interno dos organismos gera uma correspondência especular (ainda que variável, e corrigível) com um

mundo de objetos externos, independentes do viver. E que erigir ou aprimorar uma teoria 
do conhecimento é a própria razão de ser da filosofia e das ciências cognitivas. Wittgenstein (1999), em suas Investigações filosóficas, Sellars (2003, p. 14), em seu ataque ao "mito do dado", e o próprio Rorty (1995), em A filosofia e o espelho da natureza, já demonstraram, caso aceitemos suas sugestões, que as teorias do conhecimento não formam uma linhagem de respostas cada vez mais engenhosas à mesma questão universal, mas são modos de falar historicamente contingentes que, assim como podem não ser inteligíveis, nem mesmo traduzíveis, em outras épocas e culturas (pergunte o que acham disso, por exemplo, os Pirahã ${ }^{2}$, podem ser postos de lado em nossos próprios jogos de linguagem, tão logo abandonemos nossa confiança na neutralidade de um tribunal natural validando as descrições, ou seja, as reformulações da experiência, que escolhemos fazer.

Não defendo a recusa incondicional das ontologias naturalistas, em que, de todo modo, estou imerso em minhas descrições. Entendo, porém, que os fundamentos mecanicistas do afazer científico nunca exigiram que buscássemos um tribunal natural independente para validar as explicações que oferecemos. Bem como não vejo utilidade em buscar, na investigação das percepções variáveis e do comportamento resultante dos seres vivos, espelhos mais ou menos polidos da realidade. As diferenças entre as culturas humanas, como os antropólogos desde Boas sabem, e as diferenças entre as cognições humanas e não humanas, como os biólogos desde Darwin deveriam saber, não são decididas nem pelo tribunal de uma natureza lá fora (a não ser em uma caricatura adaptacionista), nem pela polidez do espelho representacionista (ou apenas para cognitivistas igualmente caricatos).

Quero propor uma historiazinha que pode me ajudar a recolocar a pergunta sobre o som da árvore que cai, ou em linhas mais gerais, sobre a percepção e sobre o ambiente, em termos um pouco diferentes. Delicate sound of thunder, da banda inglesa Pink Floyd, foi o primeiro disco de rock (não propriamente o disco, pois rodou em fita k-7) ouvido no espaço em 1988, no mesmo ano em que foi gravado, pelo seleto público de dois cosmonautas soviéticos e um francês a bordo da espaçonave Soyuz (MABBET, 2010). Além de rock progressivo, a nave transportava, para a estação espacial MIR, um equipamento "[...] dedicado à coleta e detecção de poeira cósmica e detritos espaciais" (DICATI, 2017, p. 288). Proponho que esses dois itens que a Soyuz levava em sua bagagem culturalcientífica - o disco de rock e o detector de poeira - ilustram, com suas existências não humanas, os termos de uma mesma relação que orienta o modo como tradicionalmente percebermos a percepção: a independência entre algo percebido (o objeto) e o sistema perceptivo (o sujeito).

Quanto ao disco do rock, além do nosso fetiche por feitos pioneiros (e parece que a corrida espacial sempre foi sobre isso), o que significa dizer que ele foi "o primeiro" a ser "ouvido no espaço"? Pode ser trivial apontar que, para dizermos tal coisa, é preciso que a experiência acústica seja distinguida como um gênero musical particular, por seres que partilham conosco uma rede de conversas (uma cultura) também particular. Da mesma forma, o ambiente da audição - o "espaço" - só pôde ter seu proverbial silêncio perturbado pelos solos de "Shine on your crazy diamond" no espaço (sem trocadilho) de interações em que nós, observadores (os cosmonautas lá em cima, e nós, aqui embaixo)

Ver o trabalho do linguista Daniel Everett (2009), que ilustra dramaticamente a intradutibilidade dessas noções entre os Pirahã. 
distinguimos, consensualmente, a órbita terrestre. Colocar assim a questão deixa de ser trivial, quando nos damos conta que é preciso justamente explicar como surge o fenômeno do perceber: quando nos propomos a explicar o que deve acontecer para que possamos dizer que algo está sendo percebido. Na maioria das vezes, não é particularmente errado (e de todo modo é útil) referirmo-nos à percepção como a captação de uma realidade independente, tanto nas explicações cientificas quanto em nosso viver cotidiano. Mas ao refletirmos sobre como vimos a distinguir o fenômeno da percepção, não podemos ignorar que nós, observadores, somos parte da geração do fenômeno, e, para sermos rigorosos como cientistas (e mecanicistas), precisamos explicar como surge esse observador que faz distinções. É essa a meu ver, a grande contribuição da escola chilena conhecida como Biologia do Conhecer, de Maturana e Varela $(1998 ; 2003)$, para as ciências cognitivas: propor um fundamento biológico para o ato cognitivo. A cognição como um domínio gerado no operar (no viver) de sistemas vivos, sem a ajuda protética de princípios explicativos - "dormitivos", como dizia Gregory Bateson (2000, p. xxvii) - como representações, enquadres mentais, significado ou referência. O que não quer dizer que não possamos falar em significado ou referência, descrições legítimas quanto quaisquer outras, que o observador pode fazer, e em geral faz, da história de interações organismo-meio, mas não como operações primitivas do sistema vivo (dentro das coerências explicativas que estou utilizando aqui, esteja claro). Dizemos que um organismo tem comportamento referencial quando ele aponta para um objeto. A pergunta é: como surge, no organismo, esse apontar para um objeto? Como surge o comportamento referencial?

Se olharmos agora para o detector de poeira cósmica, viramos nossa atenção no sentido inverso, do paciente percebido para o agente que percebe, e o fato de se tratar de uma mediação técnica (a ser manipulada e traduzida por um observador humano) não nos afasta um milímetro do problema colocado por sistemas perceptivos orgânicos. Como o detector (ou um organismo-que-escuta-a-árvore-que-cai) vem a perceber aquilo que percebe? Será preciso haver uma isomorfia estrutural entre o detector (ou o organismo escutador) e a poeira detectada (ou o som escutado)? Ambientes são espaços vazios aguardando ser encontrados, e preenchidos, pelo organismo? Espero não cansar o leitor se, como na peça dentro da peça de Hamlet (SHAKESPEARE, 2009), eu encaixar aqui uma historinha oferecida pelo biólogo Richard Lewontin sobre a busca de vida em Marte.

Conta-nos Lewontin (2000, p. 49-51), que o primeiro veículo de aterrissagem enviado ao planeta levava um tubo para sugar a poeira marciana para dentro de um frasco contendo um meio de cultura bacteriana. O carbono do meio recebeu uma marca radioativa, permitindo que o dióxido de carbono (liberado quando as bactérias usam carboidrato para obter energia) fosse detectado por um contador Geiger. Os cientistas se alvoroçaram quando a máquina começou a sinalizar quantidades cada vez maiores de $\mathrm{CO}_{2}$ radiativo. Mas a produção cessou subitamente, o que não acontece com culturas bacterianas em crescimento (o nível de $\mathrm{CO}_{2}$ deveria declinar gradualmente, à medida que as células começassem a morrer). Os cientistas decidiram então que não havia vida em Marte, e imputaram a produção inicial de $\mathrm{CO}_{2}$ a uma quebra catalisada por partículas de poeira. Qual era a premissa dos projetistas do detector de vida? Que havendo vida em Marte, ao se apresentar o meio de cultura, o nicho seria, como nos finais felizes das novelas, preenchido por uma forma de vida correspondente. Ou seja, ambientes existem 
independente dos organismos que os habitam. O problema é que não há como falar em ambiente ou nicho sem organismo. Ambiente é o que distinguimos em torno do organismo (gerado por sua atividade), e nicho é que o é "especificado e obscurecido pelo sistema", ou seja, pela presença (ou ação) orgânica (MATURANA, 1997, p. 86). Quando falamos em ambiente na paisagem terrestre, sempre o fazemos em relação a uma fisiologia e um viver orgânicos conhecidos (como a atividade celular que orientou o design do detector). Se não temos ideia de como são a vida e o viver marcianos, tampouco podemos distinguir a estrutura correspondente do seu ambiente ou nicho. "Talvez", conclui Lewontin (2000, p. 51), a vida marciana "seja simplesmente alérgica a açúcar!".

É curioso que Lewontin (e outros biólogos dialéticos), de um lado, e Maturana e Varela, de outro, cheguem a vocabulários diferentes abordando o problema da mesma maneira. Ao criticar a ideia de organismos acomodando-se a ambientes pré-existentes, Lewontin questiona o alcance analítico do conceito (originalmente pré-darwiniano) de adaptação. Organismos mantêm uma relação dialética, mutuamente especificadora, com seus ambientes (LEVINS; LEWONTIN, 1985), como no conceito de niche construction (LALAND; ODLING-SMEE; FELDMAN, 2001), o que é ignorado nas explicações estritamente adaptacionistas das histórias evolutiva e ontogenética das relações organismo-ambiente - ver, por exemplo, Oyama (2000). Na Biologia do Conhecer (BC), contudo, exatamente por não ser possível distinguir o ambiente sem especificar o organismo (e vice-versa), aquilo que observamos na história de relações organismo-meio é uma conservação da adaptação. Ou seja, na BC, o conceito de adaptação é fundamental, mas, na contramão das explicações neodarwinistas (em que a adaptação diferencial tem valor explicativo), ela é necessariamente invariante (MATURANA; VARELA, 1998): é uma condição para a manutenção da organização do vivo enquanto vivo. Organismos estão em acoplamento estrutural com o meio por toda a ontogenia, como condição de conservação de sua autopoiese (MATURANA; VARELA, 2003), que é como é chamada, na BC, a organização própria do vivo.

Nos termos da BC, (a capacidade de) escutar uma árvore caindo não configura uma vantagem adaptativa para determinado organismo (que, assim, estaria em melhores condições de lutar pela sobrevivência), pois tanto o organismo escutador quando seu equivalente surdo, estão, por definição, plenamente adaptados a suas "condições de existência", como Darwin (1981, p. 22), aliás, costumava dizer. Dito de outro modo, há 3,5 bilhões de anos, linhagens de organismos surdos da Terra passam bem e continuam conservando e diversificando seus modos de vida. O que não é nenhuma proeza, se lembrarmos, seguindo as coerências explicativas da BC, que "surdo" não é uma propriedade inerente ao organismo, mas uma distinção que fazemos, como observadores, da história de relações organismo-meio, ou como distinguimos o organismo constituindo seu nicho, que no caso não envolve o escutar. "Viver", diz Maturana (1997, p. 87), "é deslizar na realização de um nicho". Isso também quer dizer que só se ouviu Delicate sound of thunder pela "primeira vez no espaço", na reformulação dessa experiência que fizemos na condição de observadores. Se aceitamos o acoplamento estrutural como condição de conservação da autopoiese, devemos aceitar também que, operacionalmente, a experiência acústica dos humanos da Soyuz foi realizada, em sua deriva estrutural ontogênica, no ambiente 
continuamente trazido à mão pelo viver desses organismos. Não por serem humanos, mas por serem vivos.

\section{Como é Ser um Carrapato}

É quase um lugar-comum dizer que, ao escrever "What is it like to be a bat?", o filósofo Thomas Nagel (1974) foi feliz na escolha de seu exemplo animal para perguntar sobre a possibilidade de acesso à consciência do outro. Sobre se é possível nos colocarmos nos sapatos do outro, especialmente quando falta a esse outro, assim dizemos, a capacidade da linguagem. Ao morcego, como a outros mamíferos, costumamos conceder alguma experiência consciente, e, por outro lado, seu modo de perceber o mundo ecolocalizando, estranho à experiência humana, é o ingrediente exótico que nos deixa perplexos sobre "como é ser" um morcego. Nessa mesma linha de louvar a escolha zoológica de Nagel, Daniel Dennett (1991) concordaria que não levamos a sério a pergunta sobre como é ser um tijolo, desconfiaríamos de uma aranha com estados conscientes, e, quanto a ser um gato, ainda que levante problemas filosóficos, a pergunta não faria hesitar milhões de donos de pet que, dizemos nós, conhecemos perfeitamente as crenças, desejos e aflições de nossos bichanos. A crítica de Dennett à dúvida de Nagel nasce aí, na possibilidade de um conhecimento público do conhecimento privado. Não há, diz aquele autor, interesse em saber se realmente conhecemos a experiência consciente do outro, se o problema for a nossa (falta de) confiança nas narrativas "heterofenomenológicas" (DENNETT, 1991, p. 76), ou seja, os relatos de terceira pessoa. De fato, podemos interrogar diretamente um humano adulto, mas não um morcego de qualquer idade, sobre seus estados conscientes. Há, no entanto, humanos silenciosos. É impossível reviver a experiência auditiva de uma cantata de Bach para um morador de Leipzig do século XVIII, certamente um humano em todos os sentidos. Mas temos instrumental analítico para inferir como esse humano culturalmente alienígena respondia emocional e ideologicamente à audição bachiana, naquele tempo e lugar. O mesmo vale para o morcego. Sabemos um bocado de coisas sobre como morcegos usam seus sentidos para se orientar no mundo e, como diz o próprio Nagel no artigo seminal, humanos cegos também experimentam percepções ecolocalizadas. Enfim, Nagel propõe que a investigação empírica não nos permite conhecer como-é-ser outro ser. Dennett discorda.

No meu modo de ver o problema, seguindo muito do que eu disse anteriormente, o caso é que Nagel e Dennett, apesar de suas sérias discordâncias epistemológicas, talvez irreconciliáveis, usam consensualmente o termo "conhecer" como apreender aspectos de uma realidade objetiva. Assim, para ambos, conhecer o que outro organismo conhece é saber, com graus variáveis de confiança (segundo cada um dos autores), como ele, por sua vez, apreende seus próprios aspectos da mesma realidade. Determinar o conteúdo do conhecimento do outro, ou sua intencionalidade, em que "toda consciência é a consciência de algo" (DUPUY, 2009, p. 99). Dennett acha boa a estratégia de Nagel de não escolher um representante das aranhas como modelo para perguntar "como é ser...?" Como não vejo utilidade em estabelecer uma hierarquia de cognições, não me importo em usar um parente aracnídeo para fazer a pergunta. Como é, então, ser um carrapato? 
Nas primeiras décadas do século XX, o biólogo estoniano Jakob von Uexküll (2017) ofereceu-nos a noção de Umwelt, - ambiente, mas, também, entorno (do organismo) - que colocava em perspectiva naturalista a relação organismo-meio. Se eu disse antes que um perspectivismo naturalista é corolário da ideia de representações privilegiadas, acrescento que isso pode se aplicar a Nagel e Dennett, que debatem um acesso às "portas da percepção" (HUXLEY, 2015) de seres não linguajantes, mas, não, ao perspectivismo uexkülliano, que mira nas relações estabelecidas, e não nos termos da relação, para montar sua máquina explicativa. O organismo-tipo de Uexküll não é um mamífero, nem mesmo alguém a quem concederíamos o benefício da senciência, mas o carrapato, um acanhado acarino do gênero Ixodes. Mesmo em sua classe Arachnida, o carrapato é um modelo de humildade, principalmente se comparado às aranhas, que, embora preteridas na dúvida nageliana de "como é ser", brilham nos estudos cognitivos, em especial as construtoras de teia, pela complexa engenharia intersemiótica do seu "fenótipo estendido" (DAWKINS, 1989) 3 .

No viver do carrapato de Uexküll (provavelmente o europeu Ixodes ricinus), o mundo não está esperando lá fora, mas um admirável mundo novo é criado pelo próprio carrapato. Cega, talvez surda, a fêmea de I. ricinus deixa sua pele sensível à luz guiá-la até um ramo alto de árvore, onde aguarda (às vezes por anos) o odor do ácido butírico, emanado de um mamífero que passa pelo local, quem sabe um cachorro. É a senha para ela se soltar e abordar o animal. Se a temperatura (e, não, o cheiro) do sangue está correta, ela reconhece um hospedeiro viável e, tateando o caminho pela topografia canina, encontra uma área livre de pelagem, onde se alimenta, abandona o hospedeiro, deposita os ovos previamente fertilizados, e morre pouco tempo depois (UEXKÜLL, 2010, p. 44-45). Esse ciclo vital quase completo de uma carrapata bem-sucedido parece "pobre em mundo" - como colocava Heidegger, leitor reticente de Uexküll (BUCHANAN, 2008, p. 114) - se comparado aos humanos, ao menos à maioria deles. Mas a comparação é despropositada, pois não se trata de um concurso de paisagem percebida mais exuberante (como em certas abordagens representacionistas), mas da compreensão "biológica" - e, não, "fisiológica", nas categorias de Uexküll (2010, p. 45) - do organismo, que implica dar conta, a um só tempo, das dimensões autônoma e relacional do vivo. O carrapato seleciona, em sua deriva estrutural e suas ações, o que conta para si como mundo: seu Umwelt. Luz, odor do ácido butírico, temperatura do sangue e estímulos táteis da pelagem mamífera são sinais do mundo pois são "marcados" pelas estruturas perceptivas e efetoras do carrapato. "Falando figurativamente", diz Uexküll (2010, p. 48-49), "todo sujeito animal ataca seu objeto em um movimento de pinça - com um braço perceptivo, e outro efetor".

No âmbito dos interesses do biólogo uexkulliano, o sistema carrapato-mundo não é decomponível em polos de um movimento unidirecional, mas forma um circuito de especificações mútuas que fecha o carrapato e seu mundo pelo viver do carrapato. E o corpo do carrapato, dentro dos limites de sua pele (ou seu exoesqueleto), também interessa ao biólogo, e da mesma maneira: as partes do carrapato - órgãos, tecidos, descendo até o nível das células - não são meros componentes de uma máquina (como vê o fisiólogo), mas, em cada nível, "operadoras de máquina" (UEXKÜLL, 2010, p. 45), tal como o

Em um artigo para a revista Animal cognition, Hilton Japyassú e Kevin Laland (2017) referem-se ao operar das teias como "cognição estendida" das aranhas. 
carrapato como um todo, engendrando, cada parte, o circuito cibernético que compõe. Uexküll usa a metáfora da bolha, compreensível no vocabulário contemporâneo das redes sociais, para apontar para a autonomia do organismo e a incomensurabilidade de seus sistemas de relações, ambos delimitados por seus esféricos Umwelten. Um cão pode ser ao mesmo tempo parte do meu mundo e do mundo do carrapato, sem que os sistemas de relação se intersectem, ou que o cão seja o mesmo para os dois sistemas. Ao lado da bolha, Uexküll oferece a segunda analogia, com consequências aparentemente opostas, de uma "teoria musical da vida" (BUCHANAN, 2008, p. 26). Enquanto a bolha captura o Umwelt do organismo, cercando-o, a analogia musical aponta para fora, "demonstrando como cada organismo pode estabelecer uma relação com aspectos particulares do seu entorno" (BUCHANAN, 2008, p. 25), que, acrescento, pode ser outro ou outros organismos. Tal como os operadores de máquina, a maquinação musical também atravessa o organismo de cima abaixo (ou de dentro afora), desde as relações perceptivo-efetoras entre as partes - "ritmo celular", "melodia de órgãos", "sinfonia do organismo" -, às relações com o entorno, inclusive na constituição de comunidades intra, inter ou multiespécies, pela "harmonia de organismos" (as relações coontogênicas) até, lembrando-nos Gaia, a grande "composição da natureza" (BUCHANAN, 2008, p. 26).

Entre a bolha cibernética e a composição multinatural, Uexküll permite-nos abordar como é ser um carrapato de duas maneiras, só aparentemente contraditórias. De um lado, a descrição tem de ser sistêmica, pois "como é ser" não é um acesso privado do sujeito que conhece (como para Nagel), e tampouco um objeto disponível ao conhecimento público (como quer Dennett), mas um conhecer gerado, e encerrado, no círculo semiótico do viver do carrapato, e de um carrapato individual, diga-se. Eis a bolha. Por outro lado, "como é ser" surge continuamente nos encontros do organismo com aspectos do entorno (que podem ser outros organismos) sempre que harmônicos, ou mutuamente afetados. A analogia musical remete a constantes devir-outros, como devires deleuze-guattarianos ${ }^{4}$, em que um carrapato individual torna-se uma multidão, deslizando a cada momento de sua existência por aspectos ressonantes do meio. O odor de ácido butírico é (ou devém) como-um-carrapato, assim como o carrapato é (ou devém) como-um-odor-de-ácidobutírico (sem que "como-um" seja assemelhar-se a, ou transformar-se em outro ser), tão logo as pinças perceptivo-efetoras do carrapato se fechem ao redor desse aspecto do ambiente. E quando esse aspecto do ambiente é um organismo, dá-se o mesmo deviroutro do outro, e então há que se considerar duas (ou mais) bolhas sobrepostas, em que cada organismo é parte do Umwelt do outro e, portanto, conhece (isto é, vive), "como é ser" o outro.

Em seu Bedeutungslehre (teoria do significado), publicado originalmente em 1940, Uexküll (2010, p. 190) toma o verso de Goethe, "Se o olho não fosse como-um-sol (Sonnenhaft), ele nunca contemplaria o sol"5, e emenda: "Se o sol não fosse como-umolho (Augenhaft), ele não brilharia em nenhum céu". Organismo e ambiente perdem as posições canônicas sujeito e objeto e participam ambos do circuito cibernético como transformações, ou "diferenças", como prefere Gregory Bateson (2002, p. 64). Quando

\footnotetext{
4 Por exemplo, no volume 4 de Mil platôs (DELEUZE; GUATTARI, 1997, p. 19-20).

As versões em português são sempre minhas.
} 
parte do ambiente é outro organismo, percebemos (ouvimos?) mais de perto a analogia musical, ou "harmonia de organismos". Uexküll (2010, p. 190), novamente:

Se a flor não fosse como-uma-abelha

E a abelha não fosse como-uma-flor

A consonância nunca iria funcionar.

Harmonia de organismos não é, no entanto, só "doçura e luz", como na homenagem de Jonathan Swift (2010, p. 103) ao legado das abelhas, mas compreende as mais variadas relações. Das simbioses e socialidades ao parasitismo, à predação e à luta, passando por todo tipo de negociação intersemiótica entre organismos individuais e coletivos. A mariposa que ressoa o viver do seu predador (digamos, o morcego), não apenas é parte do Umwelt do morcego emitindo seus sinais de presa, mas em sua atenção aos sinais do predador. Talvez aqui se pudesse oferecer uma resposta substantiva à pergunta "como é ser um morcego", de Nagel, ainda que ela precisasse incluir a mariposa. Mais uma vez, Uexküll (2010, p. 207):

Se a mariposa não fosse como-um-morcego

Sua vida cedo chegaria ao fim.

\section{Máquinas e Seres Vivos}

Cibernética/ Eu não sei quando será/ Mas será quando a ciência/ Estiver livre do poder/ A consciência, livre do saber/E a paciência, morta de esperar. "Cibernética" (GIL, 1974)

Se parece que ponho na boca de Jakob von Uexküll minhas próprias escolhas epistemológicas, é porque penso nesse autor como articulando duas ideias - o circuito cibernético e a comunicação - no contexto dos organismos, que são caras às abordagens sistêmicas do viver e do conhecer (e da linguagem) que considero mais iluminadoras. Nas narrativas padrão sobre a origens das ciências cognitivas, no livro de Gardner (1996), por exemplo, a ênfase é dada no surgimento e sucesso do paradigma cognitivista, em meados dos anos 1950, e, paralelamente, no advento posterior do conexionismo, sua alternativa igualmente representacionista (DUPUY, 2009, p. 90). Mas as ciências do conhecer, na acepção atual de naturalização sistemática e multidisciplinar da epistemologia, têm pelo menos duas raízes mais heterodoxas, ambas prenhes de novas e diversificadas ontologias.

Identifico a primeira raiz nos trabalhos de Uexküll, que serviram também de inspiração para a etologia e a biossemiótica, e cujo Umwelt ressoa, em composições distintas, nas filosofias de Heidegger, Merleau-Ponty e Deleuze (BUCHANAN, 2008). A filósofa da ciência Vinciane Despret opõe o Umwelt ao movimento, característico das ciências do não humano, de tornar familiares o comportamento e a cognição animais. Em Uexküll, ao contrário, o objetivo é torná-los estranhos, fazendo-nos "sentir menos em casa" (DESPRET, 2016, p. 161) e assim ajudando-nos a nos livrar de nossas certezas, no feio termo de Dennett, heterofenomenológicas. Compartilho a decepção de Despret, quando ela aponta que o Umwelt motivou pesquisas que fazem surgir, diante de nós, animais que 
já causam estranheza em seus (assim cremos) poucos, pobres e predizíveis afetos. Que o diga o carrapato. Mas aposto também, como essa autora, em suas qualidades promissoras. Uma joia de Uexküll talvez depreciada, é a bolha, que não impõe isolamento ao vivo, ou um solipsismo no seu conhecer, mas um respeito (nosso) aos processos relacionais próprios, contingentes e de difícil tradução, de cada organismo. Vejo, nesse fechamento operacional da bolha (marca registrada dos então futuros circuitos cibernéticos), uma semelhança de família com o conceito, na Biologia do Conhecer, de determinismo estrutural, de que falo logo adiante. Tal como a bolha, essa é uma condição, e, não, uma barreira, para voltarmos a querer conversar com corpos diferentes dos nossos.

A outra raiz, ou, dizendo melhor com Deleuze e Guattari (1997), o outro plano rizomático que fez proliferar, dispersar e entrecruzar os estudos do conhecer, são as discussões transdisciplinares sobre mecanismos de "controle e comunicação" (WIENER, 1965 ) em máquinas, organismos e sociedades - ou cibernética - realizadas em Nova York entre 1946 e 1953, nas chamadas "Conferências Macy" (DUPUY, 2009, p. 3). Um de seus principais atores, o matemático Nobert Wiener, criou o termo cibernética (ou apropriou-se de um termo usado desde o século XVIII), mesma raiz de "governo", a partir do grego $\kappa v \beta \varepsilon \rho v \eta ́ \tau \eta \varsigma$, piloto de navio (WIENER, 1965, p. 11). Outro ciberneticista do primeiro time, o neurocientista Warren McCuloch, já semeara parte das preocupações da conferência em um texto com Walter Pitts (1943), propondo um "cálculo lógico das ideias imanentes à atividade neural". Se limitamos nossa atenção a Wiener e McCuloch, sem dúvida duas figuras centrais nas discussões, reduzimos o escopo das Conferências Macy à unificação de uma "ciência da mente" (DUPUY, 2009, p. 80) e à afirmação da ciência como "fabricação de modelos" (DUPUY, 2009, p. 29), ambas através da modelagem matemática do organismo, e, na mesma linha, fazendo da máquina o modelo para o comportamento do vivo. Mas as conferências renderam mais e melhores frutos, ironicamente, graças ao insucesso de seu projeto unificador. E, talvez por isso, programas vitoriosos (como a IA), baseados no cognitivismo clássico ou no conexionismo, relutem em assumir sua herança cibernética (DUPUY, 2009; VARELA; THOMPSON; ROSCH, 1997). Além de matemáticos e neurofisiólogos, as conferências atraíram uma ampla gama de cientistas naturais e sociais, com ideias às vezes conflitantes sobre a comunicação, a cognição e os sistemas sociais, ainda que a proposta cibernética de causação circular atravessasse a maioria das conversas. Margaret Mead e Gregory Bateson, por exemplo, não chegaram às Conferências Macy de mãos abanando, esperando os matemáticos lhes dizerem como modelar a sociedade a partir do organismo (e vice-versa), mas traziam a própria versão dessa causalidade circular, o movimento "cultura e personalidade", gerado no círculo linguístico-antropológico de Franz Boas, Ruth Benedict e Edward Sapir (CASTRO, 2015; DUPUY, 2009, p. 82-83).

Jean-Pierre Dupuy (2009) faz a curiosa sugestão (a partir das falas documentadas de alguns participantes) que as próprias conferências fariam parte de um experimento cibernético, em que as rodas transdisciplinares de conversa criariam seus próprios mecanismos de feedback e auto alimentação. Vejo um movimento semelhante quando Uexküll (2010, p. 45-46) descreve um diálogo hipotético entre o biólogo e o fisiólogo acerca do viver. Uexküll, claro, defende a visão do (que para ele é o) biólogo, mas o importante é que, da mesma forma que entramos no mundo do carrapato guiados pela 
mão do biólogo, se seguirmos os passos de um metaobsevador, distinguimos os diferentes Umwelten criados pelo conhecer do biólogo e do fisiólogo. Estamos no domínio, não mais da cibernética dos sistemas observados, mas dos sistemas observadores, ou "cibernética da cibernética" (VON FOERSTER, 1974), a cibernética de segunda ordem.

Heinz von Foerster, além de Mead e Bateson, estavam entre os ciberneticistas de primeira linha que contribuíram para uma cibernética de segunda ordem (DUPUY, 2009). Bateson $(2000 ; 2002)$ ajudou a popularizar, em áreas como a psicologia, a comunicação animal e as teorias da aprendizagem, a perspectiva sistêmica de uma "ecologia da mente" em que o sistema conhecedor adiciona novas camadas de diferença ao circuito do conhecer. Mas em Bateson, como em von Foerster, "informação" ainda é um conceito manejável, marcando a diferença entre os mecanismos de feedback dos circuitos cibernéticos, e os processos lineares do tipo estímulo-resposta. Citado por Dupuy, von Foerster observa que sua "máquina não-trivial processava informação, enquanto a máquina trivial behaviorista apenas reagia a um sinal" (DUPUY, 2009, p. 46, tradução minha, grifos do autor). Na escola chilena da Biologia do Conhecer, porém, não cabe falar em informação.

A epistemologia desenvolvida por Humberto Maturana e Francisco Varela (2003), em seu De maquinas y seres vivos, também é um produto da cibernética de segunda ordem, em que cognição não é uma habilidade constitutiva do sistema percebedor, mas precisa ter sua origem explicada. Em vez do observador ser um dado a priori do sistema, como nas epistemologias representacionistas, é preciso explicar como, no ato cognitivo (perceptivo ou comunicativo), surge o observador. Mas aqui já não é possível falar em informação, especialmente do modo como a biologia incorporou o conceito (ironicamente, também por influência tortuosa das Conferências Macy) em suas metáforas de codificação, transmissão e transcrição genéticas: a informação como um padrão fluindo do DNA ou do ambiente para o organismo em desenvolvimento, informando-o. Nas coerências descritivas mecanicistas da Biologia do Conhecer, um sistema (ou "máquina", qualquer unidade composta que distinguimos persistindo no tempo), se é que se presta à análise científica, é, necessariamente, estruturalmente determinado. Nada pode informar ou instruir o sistema de fora (ou a partir de algum de seus componentes), que não seja permitido, a cada momento, por sua própria estrutura. Trata-se de um imperativo epistemológico: se os sistemas admitissem interações instrutivas, eles se tornariam outra coisa ao serem analisados.

Vocês conhecem o mito do rei Midas, rei da Frígia. Ele faz algo em favor do deus Dioniso, presta-lhe algum serviço e espera alguma retribuição. E quando Dioniso lhe pergunta o que deseja como retribuição pelo serviço que lhe prestou, Midas responde: "Quero que tudo o que eu tocar vire ouro". Bem, diz Dioniso, se você quer assim, que seja. Essa é a vantagem dos deuses, que são capazes de fazer essas coisas. E Midas vai embora, feliz. Toca no copo, ouro; o manto, ouro; vai caminhando para sua casa e encontra sua filha, abraça-a e ela cai transformada numa estátua de ouro. Qual é a tragédia do rei Midas? Não pode ser um químico: qualquer coisa que ele analisar é a mesma coisa, é ouro. (MATURANA, 2001, p. 75)

Não existe, diz Maturana, o toque de Midas em ciência. E isso sabemos não apenas no contexto das explicações científicas, mas em nosso viver cotidiano. Os aparelhos eletrônicos que usamos no dia a dia (ou que as pessoas mais velhas, como eu, ainda 
usam) são bons exemplos. Se pressiono o botão do aparelho de TV e ele liga, ele funciona, sempre posso dizer que a TV, para se pôr em funcionamento, deve ser instruída pelo meu dedo, ou por meu ato de pressionar o botão. Mas se a TV parar de funcionar, não levo o meu dedo para a assistência técnica, pois sabemos que se trata de uma máquina determinada estruturalmente, e qualquer intervenção minha pode apenas desencadear, na TV, mudanças especificadas por sua estrutura.

Com os organismos ocorre o mesmo. Mas como os organismos mudam estruturalmente todo o tempo, conservando a adaptação, as consequências de se aceitar o determinismo estrutural no modo como falamos sobre a percepção, o ambiente e a comunicação (e a linguagem) do organismo, podem ser surpreendentes.

\section{O Espaço Relacional da Linguagem}

O termo "determinismo" sempre atraiu desconfiança, principalmente nas ciências humanas, e por um bom motivo: explicações deterministas costumam partir de uma noção objetiva de causalidade e implicam uma interação instrutiva, em que parte do sistema (determinismo genético, biológico) ou do seu entorno (determinismo ambiental, social, cultural) especifica como o organismo (humano ou não) irá se comportar. Determinismo estrutural, ao contrário, não se refere a uma previsibilidade do sistema, mas às condições que devem existir para que nós, observadores (humanos ou não), possamos distinguir um sistema, seja um segundo sistema, ou a nós mesmos. Além disso, devo explicitar aqui o que entendo por biologia, por conta da história de naturalização de fenômenos pertinentes ao humano, ou "colonização das ciências sociais" (ROSE, 2000) com explicações biológicas deterministas, reducionistas, ou, igualmente problemáticas, interacionistas, repartindo a causa dos fenômenos entre a natureza e a cultura. Como coloca Susan Oyama (2008, p. 51), toda fenomenologia do vivo é "biológica" (sempre implica o viver) e sempre é "adquirida", pois depende dos processos ontogênicos e coontogênicos - as relações internas e externas do sistema - para surgir, se conservar, e mudar. A biologia lida com "sistemas em desenvolvimento" (OYAMA, 2000, p. 27): não uma forma inicial, codificada nos genes, ou final, especificada por algum outro agente, mas o produto, a cada momento, das dinâmicas internas e dos processos interacionais do sistema, ou, como diz Tim Ingold (2008, p. 89), “[...] uma propriedade emergente do sistema total de relações que a possibilitam". Se é assim, devemos aceitar que tanto a rejeição como a aceitação acrítica de explicações biológicas nas ciências humanas, vêm do entendimento do biológico como um domínio de especificações deterministas e reducionistas.

Na Biologia do Conhecer (BC), o organismo é uma máquina de determinado tipo, definida por sua organização autopoiética (termo do grego, significando autoprodução e, não, auto-organização). O sistema autopoiético define-se como:

[...] uma máquina organizada como um sistema de processos de produção de componentes concatenados de tal maneira que produzem componentes que: (i) geram os processos (relações) de produção que os produzem através de suas contínuas interações e transformações e (ii) constituem a máquina como uma unidade no espaço físico. (MATURANA; VARELA, 2003, p. 69, tradução minha) 
Assim, o organismo é uma rede fechada que produz os componentes que, através de suas interações, produzem a mesma rede que os produziu, em fechamento operacional. Essa definição refere-se, primariamente, à célula (que forma uma rede de produções moleculares), mas sabemos que nós - carrapatos, humanos, árvores e morcegos - não permanecemos unicelulares por toda a vida, mas realizamos nossa autopoiese como agregados de células. Como a dinâmica celular continua participando da conservação de nossa organização, podemos ser definidos como máquinas autopoiéticas de segunda ordem.

Quando observamos um sistema vivo, distinguimos, além das relações entre seus componentes ( sua estrutura), a relação do sistema como um todo com seu entorno, e as regularidades tomadas como resultado dessa relação organismo-meio. Os movimentos e ações da totalidade do sistema vivo em um meio configuram o domínio comportamental (MATURANA; VARELA, 1998, p. 136) do organismo. O domínio onde os componentes do sistema operam (o domínio de seus estados internos, ou fisiologia) e o domínio onde o organismo inteiro interage com o ambiente (o domínio comportamental), ainda que possam ser descritos pelo observador em coocorrência, são, operacionalmente, domínios disjuntos, que não se intersectam. A dinâmica interna do organismo não especifica as interações de que o organismo participa, assim como as interações do organismo não especificam suas mudanças estruturais, ainda que possamos estabelecer uma correspondência entre a história de mudanças do organismo e a história de mudanças do meio, ou acoplamento estrutural. É a estrutura de um sistema que especifica, a cada momento, que interações ele pode ou não pode estabelecer, se são destrutivas ou mera perturbações que, independentemente de serem descritas como "más" ou "boas" pelo observador, não interrompem o fluxo do viver. O acoplamento estrutural é condição de existência do organismo, conservando a adaptação e sua autopoiese, desde seu surgimento como unidade até que o acoplamento se rompa, ou seja, que a unidade deixe de existir como sistema vivo.

Na introdução, propus a pergunta - de Maturana (1978) - sobre que processos devem ocorrer no organismo para que se estabeleça um domínio linguístico. Como o fluir comportamental modula o curso das mudanças estruturais de um organismo, o mesmo irá ocorrer quando parte do meio é outro organismo. Suas mudanças estruturais irão ocorrer em um contexto coerente com sua história de interações. E se essas interações são recorrentes e recursivas (em que as respectivas ações são incorporadas em interações subsequentes, como em uma dança), é estabelecido um "domínio linguístico" (VIANNA, 2011, p. 152). Essas relações são coontogênicas: modulam recursivamente as ontogenias respectivas dos organismos em interação. Tal como sugerido para o comportamento em geral, o domínio linguístico surge a partir do operar do organismo, mas não se confunde com ele. Ao descrever as correspondências observadas na ontogenia de dois sistemas em interação, costumamos reduzir um domínio ao outro, como no âmbito das ciências cognitivas e linguísticas, em que se descrevem os organismos em interação como se representassem a realidade de um mesmo modo em sua mente, em seu cérebro ou em seu sistema de comunicação (o código linguístico), o que não é possível dentro das coerências explicativas da $\mathrm{BC}$, que venho seguindo aqui. 
O domínio linguístico implica uma coordenação de ações: observamos as ações dos organismos em interação como uma dança comportamental recursiva. Quando um organismo, no curso de suas coordenações de ações com outro organismo, descreve aquilo que ele experiência, surge o observador (humano, na BC), que faz distinções em um domínio de coordenações consensuais com outros humanos. As próprias coordenações consensuais configuram objetos trazidos à mão pelo observador, estabelecendo uma coordenação de ações de segunda ordem, ou linguagem. Definindo assim a linguagem, a BC fecha seu ciclo explicativo, mostrando como o observador surge a partir do operar do ser vivo, e como os domínios fisiológicos e comportamentais surgem como uma operação de distinção do observador. Em meu modo um pouco diferente de responder à pergunta de Maturana, digo que é o domínio linguístico, e, não, as coordenações de segunda ordem, o espaço relacional em que são gerados tanto os fenômenos linguísticos humanos como os de qualquer organismo participante em um processo coontogênico. Proponho, então, que o termo linguagem deve se aplicar às relações coontogênicas em geral, não só as humanas (VIANNA, 2011). Entendo, no entanto, que estamos imersos em uma rede de conversas que implica o naturalismo da ciência ocidental, em que (muitos de nós) não aceitamos as interações que estabelecemos com os não humanos como consensuais e recursivas. Assim, não costumamos descrever essas interações de um modo que, nos termos da BC, permite o surgimento do observador.

Em Staying with the trouble, Donna Haraway (2016, p. 58) defende o termo simpoiese (fazer-com, ou fazer-juntos) como a descrição adequada de sistemas "complexos, dinâmicos, responsivos, situados e históricos" (HARAWAY, 2016, p. 58). Nada faz a si mesmo, nada é realmente autopoiético ou auto-organizado, diz Haraway. A mim também agrada o termo, pois, se há uma emoção recorrente no vivo, é sua irrefreável propensão de estar com o outro, desde as origens da célula bacteriana, passando pela miríade de encontros simbiontes aqui e agora, até o entrelaçamento multiespécies de Gaia, como nos ensina Lynn Margulis (1999). No entanto, embora diga que simpoiese e autopoiese estejam em "fricção gerativa" (HARAWAY, 2016, p. 61), mais que em lados opostos (desde que autopoiese não signifique autossuficiência, adverte a autora), Haraway vê qualidades indesejáveis no fechamento operacional dos sistemas autopoiéticos, e, citando um artigo sobre "sistemas auto-organizados", faz uma lista delas, como "controlados centralmente" e "previsíveis", ao passo que, em sistemas simpoiéticos, a "informação e o controle são distribuídos entre seus componentes" (HARAWAY, 2016, p. 33). Não penso que estamos falando, aqui, da mesma autopoiese da BC. Primeiro, não há como sistemas autopoiéticos se "auto organizarem", pois, a organização é uma distinção feita pelo observador, e não uma operação do organismo. E controle central e previsibilidade do sistema, como já vimos antes, também não são conceitos deriváveis da epistemologia da BC. Finalmente, quando Haraway fala de informação e controle distribuídos (entre as partes do sistema), é possível marcar uma oposição ao caminho explicativo da BC, mas apenas se Donna Haraway endossar epistemologias representacionistas (em sua vertente conexionista) o, que, conhecendo outras intervenções da autora, imagino não ser o caso. Admiro o trabalho de Haraway e, neste caso particular, compartilho, além disso, sua inclinação pelo termo simpoiese para fazer referência às múltiplas relações estabelecidas pelo vivo. Se ainda assim, aponto as inconsistências que aponto, é por 
sentir falta, nas perspectivas pós-humanistas e nas discussões em antropologia sobre as relações multiespécies, lermos com mais atenção, ou, ao menos, disposição para escutar, o caminho explicativo da Biologia do Conhecer. Tal como os organismos, a academia também vive de música, tanto quanto de Umwelt.

Uma consequência de se aceitar o modo de explicar o vivo na BC, é uma mudança em noções arraigadas sobre a cognição, ou conhecimento. Se fisiologia e comportamento são disjuntos, e a correspondência causal entre os dois é uma operação de distinção do observador, e não o operar do sistema observado, toda experiência é válida para o organismo (incluindo o humano) no momento da experiência. Se o organismo não opera com representações de uma realidade preexistente ao seu operar como ser vivo, não há experiências equivocadas, erro ou ilusão. Não podemos, como sistemas determinados estruturalmente, distinguir entre realidade e ilusão no momento da experiência. Erro e ilusão irão surgir como a reformulação da experiência na descrição de um observador, que pode ser o próprio organismo que viveu a experiência. Da mesma forma, cognição não é uma habilidade constitutiva do organismo. Se mudam as disposições de ação (a emoção), se muda a história de interações do organismo, muda a biologia, e muda a cognição. Além disso, como apontar para a cognição de um organismo é sempre uma descrição, uma reformulação da experiência (daquele que aponta para a cognição do outro), cognição não é, no momento da descrição, um dado intrínseco do sistema, mas um comportamento relativo, ou, dizendo ainda melhor, o comportamento adequado. Adequado para quem? Para aquele que aponta para o sistema. Para quem escuta.

Em Porto do Mato, Sergipe, toda manhã, dezenas de mulheres (Homo sapiens) embrenham-se no manguezal para o ritual de captura do aratu (Goniopsis cruentata), utilizando, como artifício principal, o canto. Segundo as catadoras, o canto é o elemento decisivo da captura, desencadeando e facilitando a interação com o aratu. "Se não cantar, eles não vêm" dizem, sobre o comportamento dos aratus, as catadoras de aratu (FERREIRA; VIANNA, 2019, p. 241). Se, agora, nos voltarmos para o que dizem os cientistas, iremos escutar elaborações bem diferentes do que acontece no mangue.

[...] os pesquisadores relutam em aceitar o relato de que os aratus “escutam e reagem", não havendo, na literatura científica, estudos que demonstrem uma fisiologia aratu compatível com o escutar. A hipótese é que, para reagir, o aratu deve ser capaz de captar um evento externo por meio de uma determinada fisiologia. Caso contrário, a descrição das catadoras não será aceita pela comunidade científica, pois, na experiência profissional dos cientistas, a explicação de um comportamento perceptivo só é válida se a descrição do fenômeno incluir uma descrição fisiológica correspondente. (FERREIRA; VIANNA, 2019, p. 251)

As catadoras de Porto do Mato, por outro lado, estão perfeitamente seguras sobre o que têm de fazer para o aratu "vir", e parecem ter ainda menos dúvidas sobre o pleno funcionamento auditivo desse caranguejo. No entanto, não veem a necessidade de apontar para um órgão especializado em ouvir (no aratu) para coordenar suas ações com as ações do aratu, pois reformulam sua experiência a partir das mudanças estruturais que observam no aratu em sua congruência com o meio (que inclui elas mesmas). Ou seja, no dizer das catadoras, o aratu tem o comportamento adequado - o aratu escuta 
-, validando a experiência que têm com o animal no momento em que a reformulam. As catadoras de aratu coordenam consensualmente suas ações com o aratu. Os cientistas, aparentemente, não.

Certa vez, Clifford Geertz (2001, p. 190) citou uns versos de Richard Wilbur, que dizem: "A mente é qual morcego. Exatamente/ Exceto, que na mais feliz das intelecções, um erro gracioso pode corrigir a caverna". De fato, a mente, segundo a descrição consensual que fazemos, em nossas culturas modernas, do comportamento adequado de certos organismos (para Geertz, só os humanos), tem a assombrosa capacidade de transformar a realidade. Contudo, repetindo o que eu disse em outro artigo, respondendo ao mesmo antropólogo e ao mesmo poeta, "morcegos de carne e osso também corrigem cavernas" (VIANNA, 2004, p. 174). Necessariamente. Não há contradição entre conhecer e viver, e nenhum dos dois se sentiria em casa em um ambiente - ou em uma natureza - imutável.

\section{Referências}

BATESON, Gregory. Steps to the ecology of mind. Chicago: University of Chicago Press, 2000.

BATESON, Gregory. Mind and nature: a necessary unity. Cresskill: Hampton Press, 2002. BERKELEY, George. A treatise concerning the principles of human knowledge. Indianapolis: Kenneth Winkler, 1982.

BOESCH, Christophe. Wild cultures: a comparision between chimpanzee and human cultures. Cambridge: Cambridge University Press, 2013.

BUCHANAN, Brett. Onto-ethologies: the animal environments of Uexküll, Heidegger, Merleau-Ponty and Deleuze. Albany: SUNY Press, 2008.

CASTRO, Celso (org.). Cultura e personalidade: Margaret Mead, Ruth Benedict, Edward Sapir. Rio de Janeiro: Zahar, 2015.

CHOMSKY, Noam. A Review of B. F. Skinner's Verbal Behavior. Language, [s.l.], v. 35, n. 1, p. 26-58, 1959.

DARWIN, Charles. A origem das espécies. São Paulo: Hemus, 1981.

DAWKINS, Richard. The extended phenotype. Oxford: Oxford University Press, 1989.

DELEUZE, Gilles; GUATTARI, Félix. Mil platôs: capitalismo e esquizofrenia. São Paulo: Ed. 34, 1997. v. 4.

DENNETT, Daniel. Counsciouness explained. Boston: Little, Brown and Company, 1991.

DESCOLA, Philipe. Beyond nature and culture. Chicago: University of Chicago Press, 2014.

DESPRET, Vinciane. What would animals say if we asked the right questions?

Minneapolis: University of Minnesota Press, 2016.

DICATI, Renato. Stamping the Earth from space. Cham: Springer, 2017.

DUPUY, Jean-Pierre. On the origins of cognitive sciences. Cambridge: The MIT Press, 2009.

EVERETT, Daniel. Don't sleep, there are snakes: life and language in the Amazonian jungle. New York: Random House, 2009. 
FERREIRA, Genílson; VIANNA, Beto. Canto e encanto no encontro do aratu com o humano. In: ESTEVES, Leonardo; VIANNA, Beto (org.). Desafios da alteridade: Antropologia na Universidade Federal de Sergipe. São Cristóvão: EDUFS, 2019. p. 231-262.

GARDNER, Allen; GARDNER, Beatrix. Early signs of language in cross-fostered chimpanzees. Human Evolution, [s.l.], v. 4, n. 5, p. 337-365, 1989.

GARDNER, Howard. A nova ciência da mente. São Paulo: Edusp, 1996.

GEERTZ, Clifford. Nova Luz sobre a Antropologia. Rio de Janeiro, Zahar, 2001.

GIL, Gilberto. Cibernética: (Gilberto Gil ao vivo). Gravadora: Ensaio geral, 1974. Faixa: 7:43.

GINSBURG, Simona; JABLONKA, Eva. The evolution of the sensitive soul: learning and the origins of consciousness. Cambridge: The MIT Press, 2019.

GRIFFIN, Donald. Animal minds: Beyond cognition to consciousness. Chicago: University of Chicago Press, 2001.

HARAWAY, Donna. Staying with the trouble: Making kin in the chthulucene. Durham: Duke University Press, 2016.

HUXLEY, Aldous. As portas da percepção e Céu e inferno. São Paulo: Biblioteca Azul, 2015.

INGOLD, Tim. Por que quatro porquês? In: VIANNA, Beto (ed.). Biologia da libertação: ciência, diversidade e responsabilidade. Belo Horizonte: Mazza, 2008. p. 86-94.

JAPYASSÚ, Hilton; LALAND, Kevin. Extended spider cognition. Animal cognition., [s.l.], v. 20, p. 1-21, 2017.

KREBS, John; DAVIES, Nicholas. Introdução à ecologia comportamental. São Paulo: Ateneu, 1996.

LALAND, Kevin; ODLING-SMEE, John; FELDMAN, Marcus. Niche construction, ecological inheritance and cycles of contingency in evolution. In: OYAMA, Susan; GRIFFITHS, Paul; GRAY, Russell (ed.). Cycles of contingency: developmental systems and evolution. Cambridge: MIT Press, 2001. p. 117-126.

LEVINS, Richard; LEWONTIN, Richard. The dialectical biologist. Cambridge: Harvard University press, 1985.

LEWONTIN, Richard. The triple helix: gene, organism and environment. Cambridge: Harvard University Press, 2000.

LIMA, Tânia Stolze. O dois e seu múltiplo: reflexões sobre o perspectivismo em uma cosmologia tupi. Mana, [s.l.], v. 2, n. 2, p. $21-47,1996$.

LOVEJOY, Arthur. The great chain of being. Cambridge: Harvard University Press, 2001.

MABBET, Andy. Pink Floyd: The music and the mystery. London: Omnibus, 2010.

MANN, Charles; TWISS, George. Physics. Chicago: Robert Law, 1910.

MARGULIS, Lynn. Symbiotic planet: a new look at evolution. New York: Basic Books, 1999.

MATURANA, Humberto. Biology of language: the epistemology of reality. In: MILLER, George; LENNEBERG, Elizabeth (ed.). Psychology and biology of language and thought: Essays in honor of Eric Lenneberg. New York: Academic Press, 1978. p. 28-62.

MATURANA, Humberto. O que é ver? In: MAGRO, Cristina; GRACIANO, Miriam; VAZ, Nelson. (org.). Humberto Maturana: a ontologia da realidade. Belo Horizonte: Editora UFMG, 1997. p. 77-105.

MATURANA, Humberto. Cognição, ciência e vida cotidiana. Belo Horizonte: Editora UFMG, 2001. 
MATURANA, Humberto; VARELA, Francisco. The tree of knowledge: the biologicalroots of human understanding. Boston: Shambala, 1998.

MATURANA, Humberto; VARELA, Francisco. De máquinas y seres vivos. Buenos Aires: Lumen, 2003.

MCCULOCH, Warren; PITTS, Walter. A logical calculus of ideas immanent in nervous activity. Bulletin of Mathematical Biophysics, [s.l.], v. 5, n. 4, p. 115-133, 1943.

NAGEL, Thomas. What is it like to be a bat? The Philosophical Review, [s.l.], v. 83, n. 4, p. 435-450, 1974.

OYAMA, Susan. The ontogeny of information: developmental systems and evolution. Durham: Duke University Press, 2000.

OYAMA, Susan. Mudança de hábito. In: VIANNA, Beto (ed.). Biologia da libertação: ciência, diversidade e responsabilidade. Belo Horizonte: Mazza, 2008. p. 50-54.

PINK FLOYD. Delicate Sound of Thunder. Gravadora Columbia, 1988.

REGAN, Tom. The rights of humans and other animals. In: KALOF, Linda; FITZGERALD, Amy (ed.). The animals reader: the essential classic and contemporary writings. Oxford: Berg, 2007. p. 23-29.

RORTY, Richard. A filosofia e o espelho da natureza. Rio de Janeiro: Relume Dumará, 1995.

ROSE, Hilary. Colonizing the social sciences? In: ROSE, Hilary; ROSE, Steven (ed.). Alas, poor Darwin: arguments against evolutionary psychology. New York: Harmony Books, 2000. p. 127-153.

SAVAGE-RUMBAUGH, Susan; LEWIN, Roger. Kanzi: the ape at the brink of the human mind. New York: John Wiley \& Sons, 1994.

SELLARS, Wilfrid. Empirismo e filosofia da mente. Petrópolis: Vozes, 2003.

SHAKESPEARE, William. Hamlet. Oxford: Oxford University Press, 2009.

SINGER, Peter. Animal liberation or animal rights? In: KALOF, Linda; FITZGERALD, Amy (ed.). The animals reader: the essential classic and contemporary writings. Oxford: Berg, 2007. p. 14-22.

SKINNER, Burrhus. Verbal behavior. Acton: Copley Publishing Group, 1992.

SWIFT, Jonathan. The battel of the books. In: RAWSON, Claude; HIGGINS, Ian (ed.). The essential writings of Jonathan Swift. London: W. W. Norton \& Company, 2010. p. 92-111.

TOMASELLO, Michael. Origens culturais da aquisição do conhecimento humano. São Paulo: Martins Fontes, 2003.

UEXKÜLL, Jakob von. A foray into the worlds of animals and humans: with a theory of meaning. Minneapolis: University of Minnesota Press, 2010.

UEXKÜLL, Jakob von. Theoretical biology. London: Forgotten Books, 2017.

VARELA, Francisco; THOMPSON, Evan; ROSCH, Eleanor. The embodied mind: Cognitive science and human experience. Cambridge: The MIT Press, 1997.

VIANNA, Beto. Co-ontogenia: una aproximación sistémica al lenguaje. Revista de Antropología Iberoamericana, [s.l.], v. 6, n. 2, p. 135-158, 2011.

VIANNA, Beto. Sombras na batcaverna: a charada cartesiana, o coringa kantiano e os pingüins de Darwin. Revista USP, [s.l.], n. 63, p. 169-174, 2004.

VIVEIROS DE CASTRO, Eduardo. Os pronomes cosmológicos e o perspectivismo ameríndio. Mana, [s.l.], v. 2, n. 2, p. 115-144, 1996. 
VON FOERSTER, Heinz. Cybernetics of cybernetics, Urbana: University of Illinois, 1974.

WIENER, Nobert. Cybernetics: or control and communication in the animal and the machine. Cambridge: The MIT Press, 1965.

WITTGENSTEIN, Ludwig. Investigações filosóficas. São Paulo: Nova Cultural, 1999.

\section{Beto Vianna}

Professor do Departamento de Letras de Itabaiana e do Programa de Pós-Graduação em Antropologia da Universidade Federal de Sergipe. Estuda as inter-relações entre linguagem, cultura e cognição humanas e não humanas.

Endereço profissional: Campus Universitário Prof. Alberto Carvalho. Av. Vereador Olímpio Grande S/N, Bairro Porto, Itabaiana, SE. CEP: 49506-036.

E-mail: btvianna@gmail.com

ORCID: https://orcid.org/0000-0002-7221-4943

\section{Como referenciar este artigo:}

VIANNA, Beto. Como Reatar a Conversa com Corpos Desiguais. Ilha - Revista de Antropologia, Florianópolis, v. 23, n.1, p. 50-72, 2021. 